\title{
Effect of Melting Temperature on the Wear Characteristics of Austenitic Manganese Steel
}

\author{
S.A. Balogun, D.E. Esezobor, J.O. Agunsoye \\ Department of Metallurgical and Materials Engineering \\ University of Lagos, Lagos, Nigeria.
}

\begin{abstract}
The practice in most manganese steel melting furnace is to raise the melting and pouring temperatures to $1500^{\circ} \mathrm{C}$ and above so as to enhance fluidity of the molten metal and ease removal of slag. High temperature promotes micro and macro carbide segregation of alloy elements and formation of embritting transformation products. The presence of segregation at the grain boundaries, acts as barrier to dislocation movement. This could be responsible for uneven, inconsistent wear rate and pattern of the steel.

This paper studies the effect of pouring/melting temperature on the propensity of carbide segregation of austenitic manganese steel and by translation on the wear characteristics of jaw crushers.

Austenitic manganese steel (AMS) was subjected to different heat/melt temperatures ranging from 1380 to $1550^{\circ} \mathrm{C}(\mathrm{H1}-\mathrm{H} 3)$ in an induction furnace of 1-ton capacity. Samples obtained from the edge, middle and mounting section of the heat treated steel were examined by means of optical metallurgical microscope and the relative abundance of elements was determined by means of energy dispersed X-ray (EDX) elemental spectrometer. The results indicated high segregation of alloy elements at high melting temperatures. However, uniform dispersion of carbide particles in the base of the austenitic grains was noticed at pouring temperature range of $1400-1500^{\circ} \mathrm{C}$.
\end{abstract}

Keyword: austenitic jaw crusher, manganese steel, melting temperature chrome-carbide, wear life, segregation, quenching 


\section{INTRODUCTION}

Hadfield steel invented in 1882 has an enormous capacity for work-hardening upon impact and it is commonly used for railroad components such as frogs and crossings and for rock-handling equipment. It has nominal composition of iron, 1.0 and $1.4 \%$ carbon and 10 to 14 $\%$ manganese in a 1 to 10 ratio in accordance with ASTM -A128 specification [1,2].

Due to its unique service properties, it has been used widely in a number of applications like rail tracks, dredge buckets, jaw crushers and a number of high impact and wear resistance operations with minor or no modifications in composition and heat treatment.

Many variations of the original austenitic manganese steel (AMS) are available, often in unexploited patents [2-6], but only a few have been adopted as significant improvements. These usually involve variations of carbon and manganese, with or without additional alloys such as chromium, nickel, molybdenum, vanadium, titanium, and bismuth. [7].

The mechanical properties of AMS vary with carbon and manganese content. As carbon is increased it becomes increasingly difficult to retain all of the carbon in solid solution, which may account for reduction in tensile strength and ductility. Nevertheless, as the carbon increases above $1.2 \%$, the abrasion resistance increases, while, the ductility is lowered. The carbon content is usually below $1.4 \%$ and $13 \%$ manganese due to the difficulty of obtaining an austenitic structure sufficiently free of grain boundary carbides, which are detrimental to strength and ductility [8].

In the as-cast condition, AMS contains carbides and embritting transformation product [7]. A full solution treatment can be obtained between $1000{ }^{\circ} \mathrm{C}$ and $1100{ }^{\circ} \mathrm{C}$ with soak times appropriate for the section thickness of the part. Higher solution treatment temperature (STT) should be avoided because carbon segregation may cause incipient melting, and scaling and decarburization may occur. Moreover, commercial quenching rates limit carbon concentrations retained in solution [7]. Although some grain growth may occur during solutioning, it is the pour temperature and solidification rate that strongly influence the final austenitic grain size $[1,9]$.

Carbides form in castings that are cooled slowly in the molds. Regardless of mold cooling rates, carbides are formed when the as-cast contains more than $1.0 \% \mathrm{C}[8,10]$. They form in heavy section castings during heat treatment if quenching is ineffective in producing rapid cooling throughout the entire section thickness. Carbides can form during service at temperatures above about $275^{\circ} \mathrm{C}$.

Heat treatment involving solution annealing and quenching in water can enhance yield strength and abrasion resistance [11]. However, as the section size of manganese steel increases, tensile strength and ductility decrease substantially in heat treated castings [7]. This occurs 
because heavy sections do not solidify in the mold fast enough to prevent coarse grain size. This condition can not be altered by heat treatment. At a given temperature and grain size, nickel and manganese additions are beneficial for enhancing impact strength $[10,12]$, while higher carbon and chromium levels are not.

The continuous development of industry, and, in particular, mining and metallurgy in Nigeria, coupled with the government favorable policy and on the local content demands are ever increasing use of mining metal parts, working under hard impact-abrasion conditions, where high manganese steels are found to be among the best. Combination of high strength, density and plasticity together with capability of Hadfield manganese steel to increase several times the surface hardness under impact load, as well as relative simplicity and cheapness of its production, ensured its wide use.

In Nigeria, the AMS is widely used in the mining industry as wear plates of cone and jaw crushers. Majority of these jaw crushers were imported into the country until recently when a number of local foundries in Nigeria began to produce jaw crushers [13]. However, the locally produced jaw crushers are characterized with high level of reject (15-25\%) due to the appearance of cracks after mould-shakeout, during fettling, and after heat treatment.

This paper studies the effect of pouring temperature on the propensity of carbide segregation of AMS and consequently on the wear characteristics of jaw crushers.

\section{MATERIALS AND METHODS}

\subsection{Melting and Casting}

$380 \mathrm{Kg}$ of manganese returns with $450 \mathrm{Kg}$ steel scraps, $15 \mathrm{Kg}$ ferro-chrome, $110 \mathrm{Kg}$ ferro-manganese and $3 \mathrm{Kg}$ ferro-silicon were melted in an induction furnace of 1-ton capacity to obtain the typical local jaw plate composition. The quantity and chemical composition of the charge make-up are shown in Table 1. The resultant spectrometric analysis of the New Spec Jaw Plate (NSJP) is shown in Table 2.

Three batches of the materials weighing $330 \mathrm{~kg}$ each were subjected to three different heat/melt temperatures shown in Table 3.

The molten metals were cast into preheated sand moulds. The mould is made from sodium silicate bonded sand mixture in accordance with BS14 standard. The surface temperature of the cast was measured at various points with the aid of a digital probe pyrometer. Removal of the mould was done 32 hours after the casting. 
Table 1. Estimated charge make up.

\begin{tabular}{|l|c|c|c|c|c|c|c|c|c|}
\hline \multirow{2}{*}{$\begin{array}{c}\text { Charge } \\
\text { Material }\end{array}$} & $\begin{array}{c}\text { Charge } \\
\text { Weight, Kg }\end{array}$ & \multicolumn{7}{|c|}{ Element Composition, (\%) } \\
\cline { 2 - 11 } & & C & Si & Mn & P & S & Cr & Mo & Ni \\
\hline Returns & 380 & 1.31 & 0.66 & 12.10 & 0.03 & 0.03 & 1.82 & - & - \\
\hline $\begin{array}{l}\text { Steel } \\
\text { Scraps }\end{array}$ & 450 & 0.43 & 0.32 & 0.32 & 0.21 & 0.21 & - & - & - \\
\hline $\begin{array}{l}\text { Ferro } \\
\text { Chrome }\end{array}$ & 15 & 0.64 & - & - & - & - & 61.95 & - & - \\
\hline $\begin{array}{l}\text { Ferro } \\
\text { Manganese }\end{array}$ & 110 & 4.33 & - & 55.48 & - & - & - & - & - \\
\hline $\begin{array}{l}\text { Ferro } \\
\text { Silicon }\end{array}$ & 3 & - & 70.25 & - & - & - & - & - & - \\
\hline Total & 958 & 1.23 & 0.63 & 13.57 & 0.02 & 0.02 & 1.69 & - & - \\
\hline
\end{tabular}

Table 2. Chemical composition of manganese steel, $\%$.

\begin{tabular}{|c|l|c|c|c|c|c|c|c|c|c|}
\hline s/n & \multicolumn{1}{|c|}{ Description } & $\mathbf{C}$ & $\mathbf{S i}$ & $\mathbf{M n}$ & $\mathbf{N i}$ & $\mathbf{P}$ & $\mathbf{S}$ & $\mathbf{C r}$ & $\mathbf{A l}$ & $\mathbf{F e}$ \\
\hline 1 & $\begin{array}{l}\text { Standard Hadfield } \\
\text { Manganese Steel }\end{array}$ & $\begin{array}{l}1.00- \\
1.30\end{array}$ & $\begin{array}{l}0.50- \\
0.80\end{array}$ & $\begin{array}{l}12.00- \\
14.00\end{array}$ & - & $\begin{array}{c}0.005 \\
\max \end{array}$ & $\begin{array}{c}0.005 \\
\max \end{array}$ & - & & $\mathrm{Bal}$ \\
\hline 2 & $\begin{array}{l}\text { New Spec Jaw Plate } \\
\text { NSJP) }\end{array}$ & 1.23 & 0.60 & 12.80 & - & 0.005 & 0.006 & 2.40 & - & $\mathrm{Bal}$ \\
\hline 3 & $\begin{array}{l}\text { Typical Local Jaw } \\
\text { Plate * }\end{array}$ & 1.27 & 0.90 & 12.6 & 0.40 & 0.60 & 0.05 & 2.10 & 0.08 & $\mathrm{Bal}$ \\
\hline 4 & $\begin{array}{l}\text { Foreign Manganese- } \\
\text { Jaw Plate }\end{array}$ & 1.02 & 0.50 & 13.00 & 0.077 & 0.002 & 0.001 & 1.40 & 0.006 & $\mathrm{Bal}$ \\
\hline
\end{tabular}

*Typical local jaw plate contains $0.06 \% \mathrm{Mo}, 0.05 \% \mathrm{~V}$ and $0.16 \% \mathrm{Sn}$

Table 3. The Batch/Heat and its corresponding pouring temperature.

\begin{tabular}{|l|c|c|r|}
\hline HEAT & H1 & H2 & H3 \\
\hline TEMP ${ }^{\circ} \mathrm{C}$ & 1550 & 1450 & 1380 \\
\hline
\end{tabular}




\subsection{Heat Treatment}

The jaw plates were austenitized in an industrial muffle furnace at a temperature of $1050^{\circ} \mathrm{C}$ for 4 hours.

The different set of samples were soaked for $5 \mathrm{~min}$ in a 10,000-litre water tank fitted with $10 \mathrm{HP}$ submersible pumps to ensure that no vapor formation occurred during quenching at the interface of hot casting and the water for quenching.

The entire surface of the sample was tested using a piece of magnet (horseshoe) after shot blasting to confirm the degree of full-austenitic transformation.

\subsection{Microstructure}

Samples with dimensions $25 \mathrm{~mm}$ x $25 \mathrm{~mm}$ x $12.5 \mathrm{~mm}$ were obtained from the edge (a), middle i.e. thickest section (b), and the mounting section (c) of the heat treated jaw crusher plate. The surface of the sample was prepared for metallographic examination using nital as etchant after preliminary grinding and polishing operations. An optical metallurgical microscope was used to obtain $250 \mathrm{X}$ photomicrographs of the processed samples. The micrographs are shown in Figures 1, 3 and 5. The relative abundance of element on samples surface showed in Figures 2, 4 and 6 were determined by Energy Dispersed X-ray (EDX) elemental spectrometers in accordance with ASTM F 1375-92 (2005).

\subsection{Wear Characteristics}

The performances of the local and foreign jaw plates along side with the NSJP produced at H1 were monitored in Ratcon Quarry. The Utility of the plate in percent was evaluated as

$$
\text { Utility }=\frac{\text { Initial weight }- \text { Final weight }}{\text { Initial weight }} \times 100 \%
$$

The initial weight of all the samples of the plates was $1018 \mathrm{~kg}$.

\section{RESULTS AND DISCUSSIONS}

The micrographs of the selected three sections of the plate at $\mathrm{H} 1$ reveal non-uniform distribution of carbides in the austenite matrix (see Figure 1). High concentration of carbide particles was noticed at the grain boundaries at higher temperature. The relative abundance of alloy element as shown by EDX examination also reveals high degree of chromium and manganese segregation (Figure 2.) 


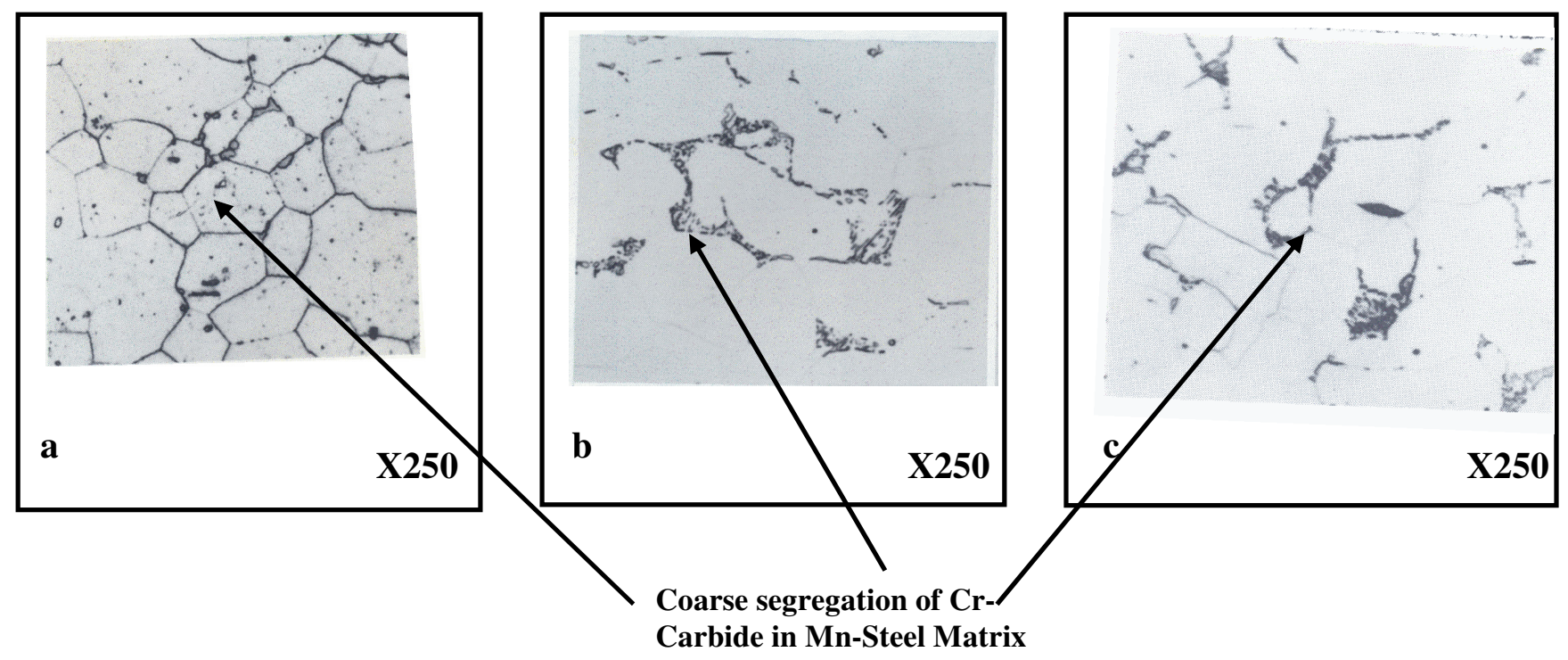

Figure 1. The Microstructures of the edge (a), middle (b) and mounting(c) sections of the jaw crusher plate at $\mathrm{H} 1$. These microstructures are characterized by the presence of irregular. segregated chromium carbides around the grain boundarv.
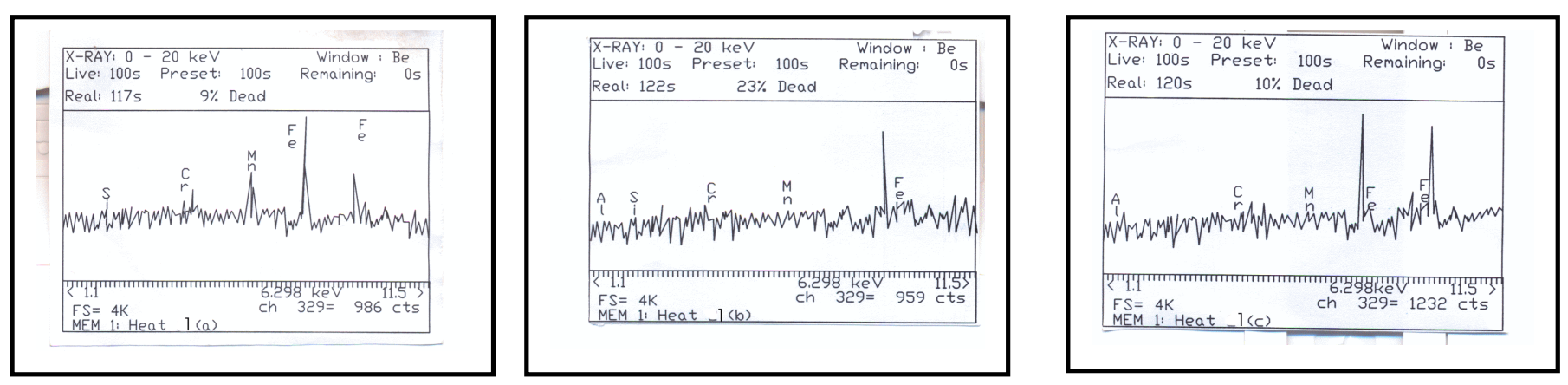

Figure 2. Relative Abundance of elements at H1.

At $\mathrm{H} 2$, few carbide particles are seen dispersed in the austenite matrix (Figure 3). The segregation of alloy elements is also indicated in the EDX scan. However the extent of segregation is at a lower level. The scans are characterized by the presence of uniformly distributed semi fine-dispersed chromium carbide within its matrix (Figure 4). 


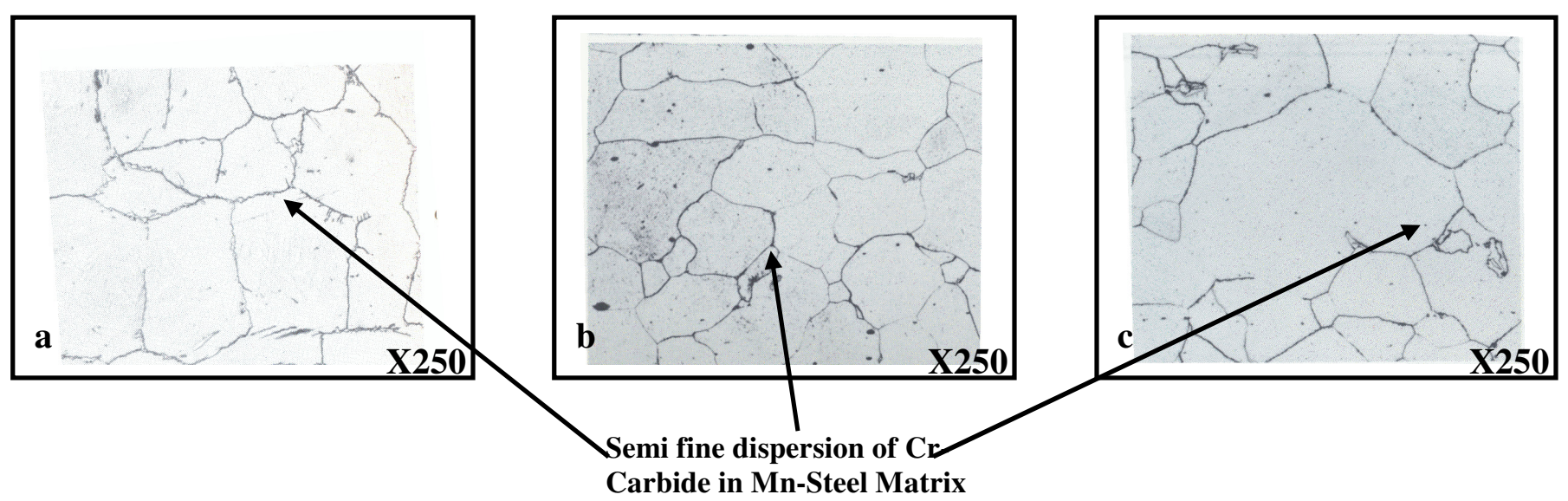

Figure 3. The Microstructures of the edge (a), middle (b) and mounting (c) sections of the jaw crusher plate at $\mathrm{H} 2$.
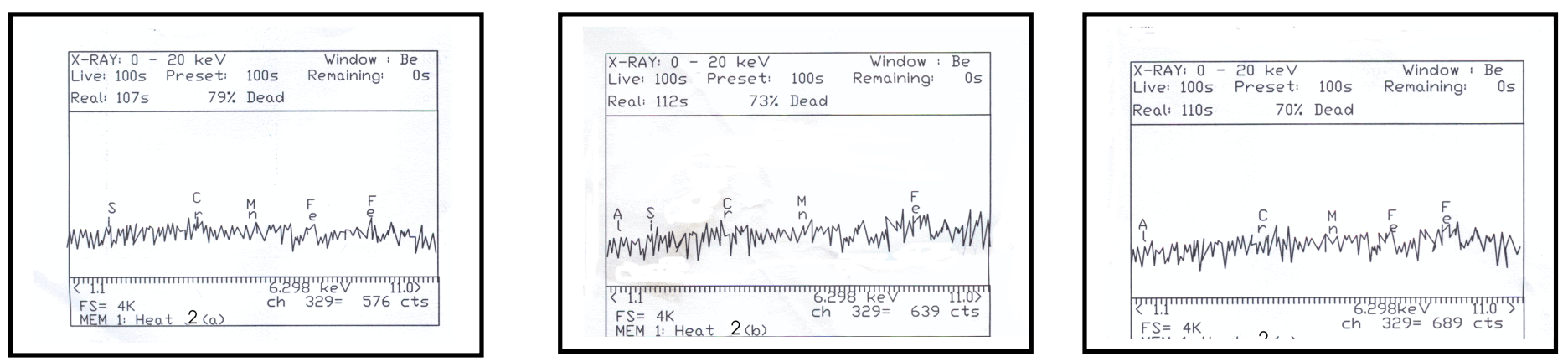

Figure 4. Relative Abundance of Element at $\mathrm{H} 2$

The micrographs of the plates at $\mathrm{H} 3$ as shown in Figure 5 do not show any concentration of carbides at the grain boundaries of the austenite matrix. The dark carbide particles are observed to be uniformly dispersed in the matrix. The results of the EDX scan in Figure 6 also reveal a very minimal degree of segregation.

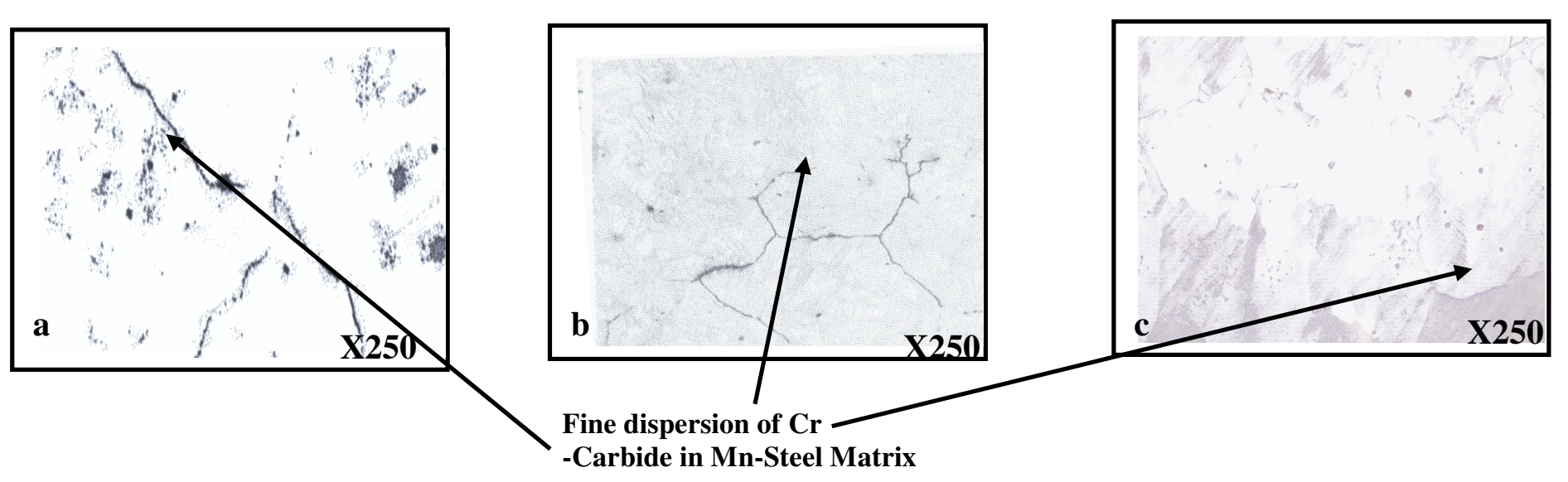

Figure 5. The Microstructures of the edge (a), middle (b) and mounting (c) sections of the jaw crusher plate at $\mathrm{H} 3$. 

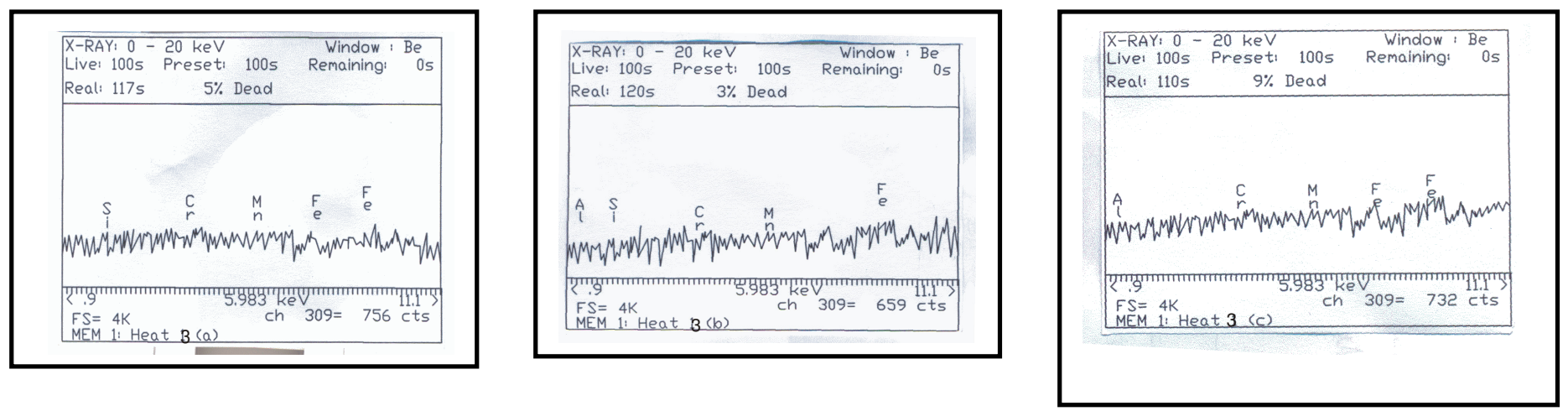

Figure 6. Relative Abundance of element at H3.

The results obtained in Figures 1-6 show a steady increase in segregation as the melting temperature increases. At high temperatures, the high segregation observed is due to the increased solidification time as a result of wider solidification (i.e. liquidus/ solidus lines) range. In industrial practice, high pouring temperatures is usually carried out mainly due to poor furnace linings / refractories. This leads to rapid heat loss and in an effort to compensate for the heat loss, the furnace temperature is usually increased to temperatures above $1600{ }^{\mathrm{O}} \mathrm{C}$, superheating the melt in the process.

The relative abundance of the alloy elements at various melting temperatures as shown in the EDX curves substantiates the segregation of these elements in the austenite matrix.

Figure 7 below shows that the silicon element remains uniformly distributed in the austenite matrix irrespective of the pouring temperature, i.e. there is little or no silicon segregation in the structure. However, there is a sharp increase in segregation of chromium as the pouring temperature increases beyond $1450{ }^{\circ} \mathrm{C}$. The manganese steel contains higher amount of chromium, $2.4 \%$ (see Table 2), which leads to the formation of a large quantity of coarse carbide, whose distribution in the grain boundaries is non-uniform and segregates at the grain boundary.Segregation as a phenomenon is due to the wide differential cooling of the casting in the mould, which is a direct function of the pouring temperature (see Figure 7). The most significant factor is the peak temperature of melting, since at high temperature, melting process guarantees segregation, which once formed can not be reversed by altering pouring temperature. 


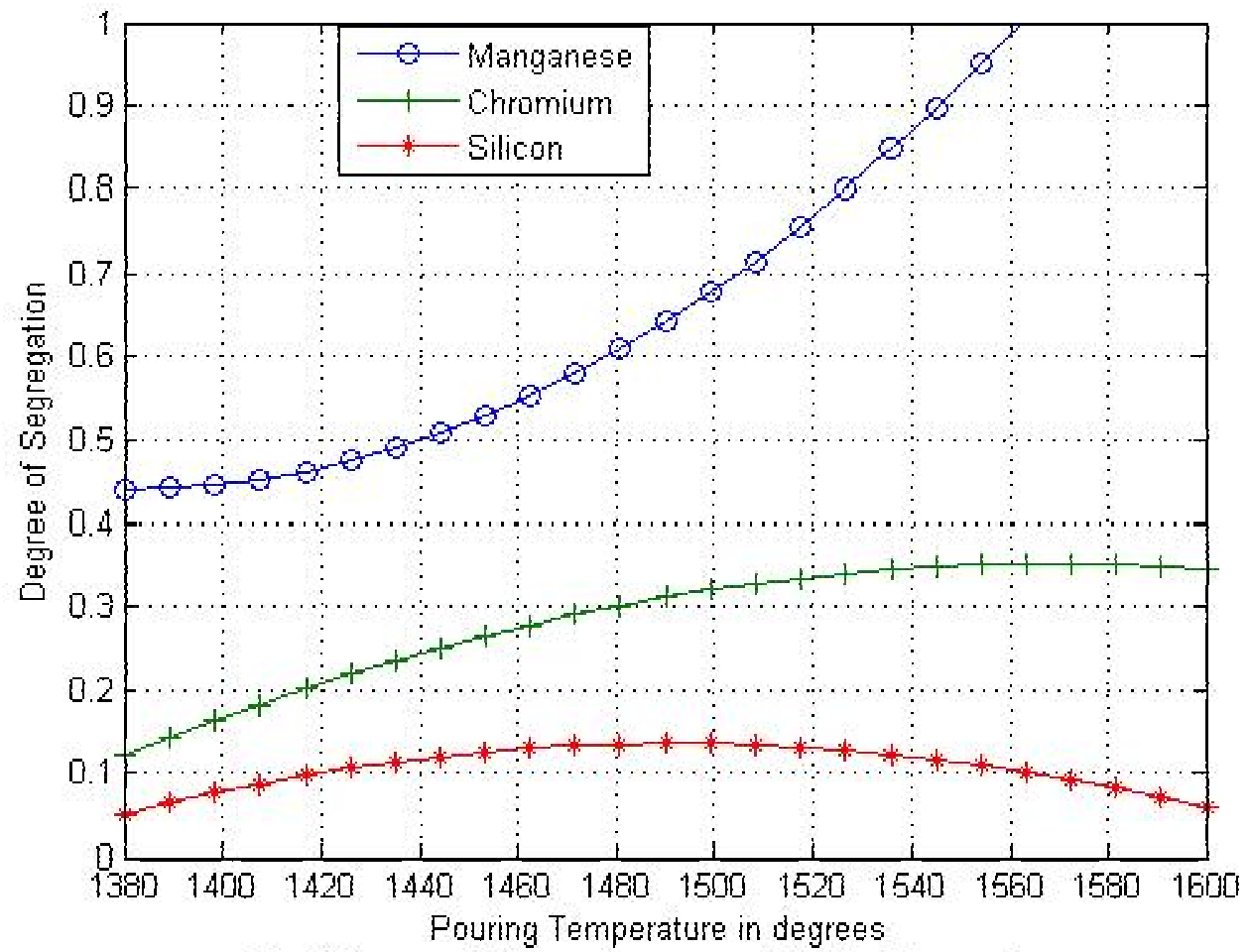

Fig 7 Degree of Segregation wersus Fouring Temperature

The practice in most local foundries is to melt and pour at very high temperatures $(\geq 1500$ ${ }^{\circ} \mathrm{C}$ ) as a means to enhance fluidity of the melt and ease removal of slag, particularly in an induction-melting furnace. This practice has been found to be counter productive because melting above $1500{ }^{\circ} \mathrm{C}$ encourages excessive slag formation as a result of the reaction between manganese and the refractory lining. This phenomenon enhances superheating that hastens the erosion of furnace lining. This may eventually leads to furnace leakage; where metal could penetrate through refractory wall. This practice employed by the local foundry shortens the life of the furnace. Resulting repair or complete replacement are both time consuming and uneconomical.

The summary report of the jaw plate performance as monitored in Ratcon Quarry for 6 weeks along side the performance of the new spec produced through $\mathrm{H} 3$ is presented in Table 4.

The result shows that the wear pattern across the operational surface of NSJP is uniform compared to the wear on the local jaw plates. 
The locally produced crusher plate is characterized by inconsistent and uneven wear rate when compared to the foreign crusher of equivalent specifications. Investigation conducted at local client/quarry company operations revealed that at equivalent composition and shapes of the crusher under the same condition of service, the local crusher plate produced 150,000 tones of crushed rock compared to 170,000 tones and 200,000 tones produced by the NSJP and the imported plates respectively (Table 4).

Table 4. The summary report of the jaw plate performance as monitored in Ractcon Quarry for 6 weeks.

\begin{tabular}{|c|c|c|c|c|}
\hline Batch & \multicolumn{2}{|c|}{ Crushed rock (,000 tons) } & NSJP (H3) rushed rock (,000 tons) \\
\hline & $\begin{array}{c}\text { Local plate, } \\
\mathrm{J}_{\mathrm{L}}\end{array}$ & $\begin{array}{c}\text { Imported plate, } \\
\mathrm{J}_{\mathrm{I}}\end{array}$ & $\begin{array}{c}\text { NSS } \\
\mathrm{J}_{\mathrm{S}}\end{array}$ & $\begin{array}{c}\text { increase of from } \\
\text { local plate }\end{array}$ \\
\hline 1 & 146.5 & 192.4 & 172.4 & 17.7 \\
\hline 2 & 139.5 & 196.1 & 175.4 & 25.7 \\
\hline 3 & 152.7 & 198.5 & 170.3 & 11.5 \\
\hline 4 & 149.4 & 200.2 & 169.5 & 13.5 \\
\hline 5 & 153.0 & 198.6 & 169.6 & 10.9 \\
\hline 6 & 148.6 & 199.3 & 171.4 & 15.3 \\
\hline
\end{tabular}

$\%$ increase of crushed rock $=\frac{J_{S}-J_{L}}{J_{L}} \times 100$

The schematic diagram of used imported and local plates of jaw crushers are shown in figures 8 and 9 respectively. Although the wear rate of the foreign plate may be faster than the wear rate of the local or new spec plates (see Table 5), the wear in the former is uniform, while the wear behavior of the local is uneven leading to variable feed sizes. The uneven wear behavior of the local plate can be attributed to the pronounced segregation of chromium carbide $\left(\mathrm{Cr}_{\mathrm{x}} \mathrm{C}\right)$ in the austenite matrix at grain boundaries

Table 5. The weight loss of the jaw plate during 6 weeks operations.

\begin{tabular}{|c|c|c|c|c|c|c|}
\hline \multirow[b]{2}{*}{ Batch } & \multirow[b]{2}{*}{$\begin{array}{c}\text { Local plate, } \\
\mathrm{J}_{1}\end{array}$} & \multirow[b]{2}{*}{$\begin{array}{c}\text { Imported plate, } \\
\mathrm{J}_{\mathrm{I}}\end{array}$} & \multirow[b]{2}{*}{$\begin{array}{c}\text { NSJP, } \\
\mathrm{J}_{\mathrm{S}}\end{array}$} & \multicolumn{3}{|c|}{ Utility, \% } \\
\hline & & & & local plate & imported plate & NSJP \\
\hline 1 & 139.5 & 215.8 & 193.4 & 13.7 & 21.2 & 18.9 \\
\hline 2 & 112.0 & 239.2 & 153.2 & 11.0 & 23.5 & 15.1 \\
\hline 3 & 139.7 & 210.0 & 190.8 & 13.6 & 20.6 & 18.7 \\
\hline 4 & 144.2 & 225.7 & 152.6 & 14.2 & 22.2 & 14.9 \\
\hline 5 & 147.6 & 219.9 & 150.7 & 14.5 & 21.6 & 14.8 \\
\hline 6 & 136.4 & 208.7 & 148.3 & 13.4 & 20.5 & 14.6 \\
\hline
\end{tabular}


wornout imported plate

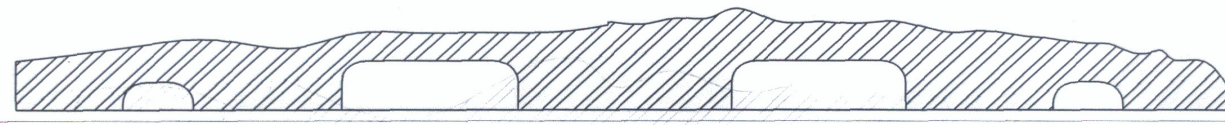

Figure 8. Worn-out plate of imported jaw crusher

wornol

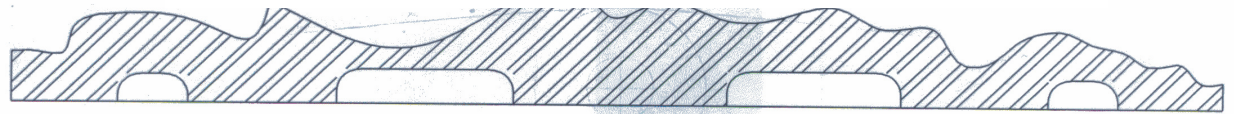

Figure 9. Worn-Out Plate of Local Jaw Crusher.

The presence of chromium in purely austenite Hadfield manganese steel leads to the appearance of cracks due to elevated internal stresses associated with the liberation of carbides, which may segregate, mainly at the grain boundary. At high temperatures, segregation is very severe. There is little or no elemental segregation at temperatures between $1370^{\circ} \mathrm{C}$ and $1400{ }^{\circ} \mathrm{C}$ (see Figure 5). Hence, a jaw crusher produced at this range of temperatures will exhibit better wear properties.

On the other hand, there is evidence of high degree of segregation at melting temperature of $1550^{\circ} \mathrm{C}$ (see Figure 3). As the melting temperature is reduced, the order of dispersion of carbides in the matrix reduces, while, at $1450{ }^{\circ} \mathrm{C}$ the carbides are relatively less dispersed in the matrix. Segregation impedes the movement of dislocation around the grain boundaries where aggregate of $\mathrm{CrC}$ particles is highly pronounced.

The conventional solution heat treatment of the jaw crusher employed by local foundries does not eliminate the segregation as this can only impact positive effect on the microstructure. The macro segregation of alloying elements remains unaltered by solution heat treatment.

\section{CONCLUSION}

EDX analysis has shown that high pouring temperature above $1450{ }^{\circ} \mathrm{C}$ should be discouraged as it promotes segregation on the micro and macro levels. The presence of segregation particularly in locally produced manganese steel is responsible for its uneven, 
inconsistent wear rate and pattern. The segregation around grain boundaries acts as barrier and impedes the movement of dislocation around the grain boundaries where the $\mathrm{Cr}-\mathrm{C}$ segregation is highly pronounced. The increased metallic inclusion through back charging with foundry returns depreciates the ratio of mobile dislocation to immobile dislocation to a value lower than unity. This ratio translates to higher densities of immobile dislocation and subsequently poor work hardening property of the AMS. Thus, the material is favoured to fail by cracking when the energy of the mobile dislocation becomes lower than the energy of the immobile dislocation.

The pouring temperatures of $1400-1450{ }^{\circ} \mathrm{C}$ will promote uniform dispersion of carbide particles within the structure and thereby enhancing the wear property of the jaw crusher [1,9]. However, the low pouring temperatures diminish the fluidity of the molten metal and results in casting defects, low yield put and high operational costs.

This phenomenon of segregation, arising from high temperature pouring can be reduced by using neutral refractory to line the lip pouring ladles as against the current practice of using $\mathrm{CO}_{2}$ sand. This will conserve heat in the ladle and reduce the rate of temperature drop. In the alternative, the use of bottom-pour ladle should be considered.

Finely dispersed carbides formed during cooling in the segregation zones promote efficient hardening of steel [1]. The uniformly distributed chromium carbides in the base of the austenitic grains provides higher resistance to impact abrasion wear, which improves the strength and work hardening of the plate under repeated and severe impact.

\section{ACKNOWLEDGMENTS}

The authors acknowledge financial support by grants from the Nigerian Foundries Limited, Ilupeju Industrial Estate Lagos and the exclusive use of her facilities to carry out this study.

The authors would like to express sincere thanks to Engineer Anandar, the Factory Manager of Racton Quarry, Ibadan for his support during onsite monitoring and data collection from his company and also Teniola Sadiz who facilitated the EDX scan in Orarobot University, Scotland.

\section{DISCLAIMER}

The material in this paper is intended for general information only. Any use of this material in relation to any specific application should be based on independent examination and verification of its unrestricted availability for such use, and determination of suitability for the application by professionally qualified personnel. No license under any patents or other 
proprietary interest is implied by the publication of this paper. Those making use of or relying upon the material assume all risks and liabilities arising from such use or reliance.

\section{REFERENCES}

1 Avery, H.S., “Austenitic Manganese Steel” Metals Handbook, American Society for Metals, volume $1,8^{\text {th }}$ edition, 1961 pp. 834 to 842

2. Steel Founders Society. Steel Castings Handbook. $5^{\text {th }}$ Edition, 1980

3. Patent No 5601782. Saburo Kunioko Hiroshi Toriyama. Abrasive Resistant High Manganese Cast Steel. Appl. No 532768 issued 11:02. 1997 filed 27.09-1995

4. USA patent 4394168. Hartving Tor, Fjeucheum Petter. Austenitic wear resistant steel. Appl. No 230630 filed 02.02. 1981 publ. 19.07. 1983

5. Patent CA 1221560 KOS Bernd. Work hardenable austenitic manganese steel and method for the production thereof. Appl. (21) 439018 issued 12 may 1987 filed Oct 14. 1983

6. European Patent EP 1337679. Kucharczyk Jerzy Funk, Karl Kos Bernd. Grain-refined austenitic manganese steel casting having micro-additions of vanadium and fibranium and method of manufacturing. Appl EP 20010979440 Date 03:10 2001 publ. 27/08/2003

7. Tasker, J., Austenitic Manganese steel-fact and fallacy. Intermountain Minerals Symposium. Vail; Colorado, 3-6 August, 1982 pp 3-19

8. Subramanyam, D.K.; Swansieger, A.E and Avery, H.S., “Austenitic Manganese Steels". ASM Metal Handbook, American Society of Metals, Volume 1, Tenth Edition, 1990, pp. 822 to 840.

9. American Society for Metals. Metals Handbook $9^{\text {th }}$ Edition Vol 3. Properties and Selections: Stainless Steels, Tool Materials, and Special Metals. ASM, 1980

10. Avery, H.S., “Austenitic Manganese Steel for Railway Trackwork”, Case Report Number 429-12, Abex Corporation Research Center, Mahwah, New Jersey, September 1981, $39 \mathrm{pp}$

11. Muki Satya Permana. Casting practice of Hadfield manganese steel alloy and effect of solution treatment on its microstructure. Master Theses for JBPTITBPP/2001-09-11

12. Effect of deformation temperature and heat treatment on the structure and properties of high-manganese steel. Metal Science and Heat treatment. Vol 13 No5, May, 1971 p. 390392

13. Machine Shop Production Report. Nigeria foundries Limited Ilupeju, Lagos, Nigeria 1998 